Journal of Engineering Sciences, Assiut University, Vol. 40, No. 5, pp.1375-1388 - September 2012.

\title{
A MODEL FOR DIELECTRIC CHARACTERIZATION OF NANOCOMPOSITE POLYMERIC INDUSTRIAL MATERIALS
}

\section{A. Thabet and Y. A. Mobarak}

Aswan, Nanotechnology Research Centre NTRC, Faculty of Energy Engineering, South Valley University, Aswan, Egypt.

(Received July 10, 2011 Accepted December 8, 2011)

Interphase Power Law IPL model is based on a simple extension of a general power law model in which composite system containing filler interphase and matrix regions may be treated as a unique three-component composite system comprising two primary components (matrix and filler) and an interphase region that is inextricably dependent upon the characteristics of the filler and matrix components. In this paper, it can be investigated that all possible causes and effects of the interphase region on a variety of complex composite systems and so, the effects of the composite filler types and filler surfaces areas as well as the dielectric characteristics of the interphase region have been investigated. Effects of the composite filler types and filler surface areas as well as the dielectric characteristics of the interphase region have been explored on new industrial materials. Finally, this research explains the dielectric characteristics of new nanocomposite polymeric materials by IPL.

Keywords: Dielectric Properties, Polymeric Industrial Materials.

\section{INTRODUCTION}

Power law model relationships are used in dielectric modeling of composite systems [1-6]. The general two component power-law model for complex permittivity has been used extensively for a wide range of material systems with varied success, including air-particulate composites [2], ceramic-ceramic composites [3] and polymerceramic composites [4]. Research into the physical and electrical characteristics of particulate filled polymer composites has supported the existence of interphase regions at polymer-dispersant interfaces [7-10]. It should be noted that, IPL model in its general form, is commonly known as the Lichtenecker-Rother equation. However, a clear distinction exists between the IPL model and the Lichtenecker-Rother LR model.

IPL model is unique in that it incorporates two independent components of the composite as well as an interphase region that is dependent upon the characteristics of the two components. This model thus does not rely on three independent components but rather two independent components and the interphase region between them. The LR model is based on a composite consisting of three independent constituent components with no interactions between the components. It is important to recognize the distinction between the IPL model and a standard three-component power-law mixture. The determination of the interphase thickness is further described in detail in [11-14]. The interphase overlap probability, arises from the proximity of the individual filler particles. When the filler particles come close together, the interphase regions 
surrounding each filler particle begin to overlap, thereby reducing the effective interphase volume fraction. The interphase overlap probability is a function of the filler volume fraction, interphase thickness and the shape and size of the filler particles. Approximations have been developed to estimate the overlap of such particles using Monte Carlo simulations or alternately analytical solutions to percolation models [15, 16].

In our analyses, a general interphase overlap probability function, was developed for spherical particles [17]. The values of nanocomposite permittivity can reduce to values below that of the unfilled polymer if the polarization mechanisms in the bulk of the material are restricted. In the case of a nanocomposite system, it has been observed that the reduction in the values of effective permittivity is probably due to hindrances in the mobility of Epoxy chains in the bulk of nanocomposite [18- 20]. A general interphase overlap probability function has been developed for spherical particles. In several investigations, this interphase region has been shown to have significantly different properties compared to the bulk resin. In recent years, polymer nanocomposites have been extensively studied in optical, thermal and mechanical properties, but there has been relatively little research into dielectric properties [21]. This work studies the effect of filler volume fraction on effective dielectric constant for selected polymers with selected nano-filler as a nanocomposites industrial materials, which will be new costless industrial materials.

\section{INTERPHASE THEORY}

The interphase region is comprised of polymer molecules that are bonded or otherwise oriented at the matrix-filler interface. This interfacial-bonding region is termed the interphase and results from the confining effect that the rigid filler particles have on the mobility of the polymer molecules in the matrix. In the bulk matrix regions of the composite, the polymer chains adopt random orientational configurations. The polymer chains and side groups are relatively free to move stretching, twisting and wagging to minimize their conformational energy and maximize their internal entropy. When bonded to the filler surface, however, the polymer molecules are restricted in movement. An estimation of the effect of the change in the dielectric constant as a result of the chemical bonding of the polymer matrix at the filler surface of a composite system can be calculated using molecular polarizability equations [10]. The change in dielectric constant for the polymer material in the interphase region is proportional to the increase or decrease in the dipole polarization. A more complete description of the dipole polarization within the interphase region of a composite system and the resulting dielectric constant calculations is given in ref. [11]. This paper has described a simple interphase model capable of providing additional insight to both the real and imaginary parts of the complex permittivity of composite systems incorporating the interphase theory. The composite system containing filler, interphase and matrix regions is illustrated in Fig.1. A composite system comprising two primary components (matrix and filler) and an interphase region may be treated as a unique three-component composite system in which the interphase volume is inextricably dependent upon the characteristics of the filler component. 

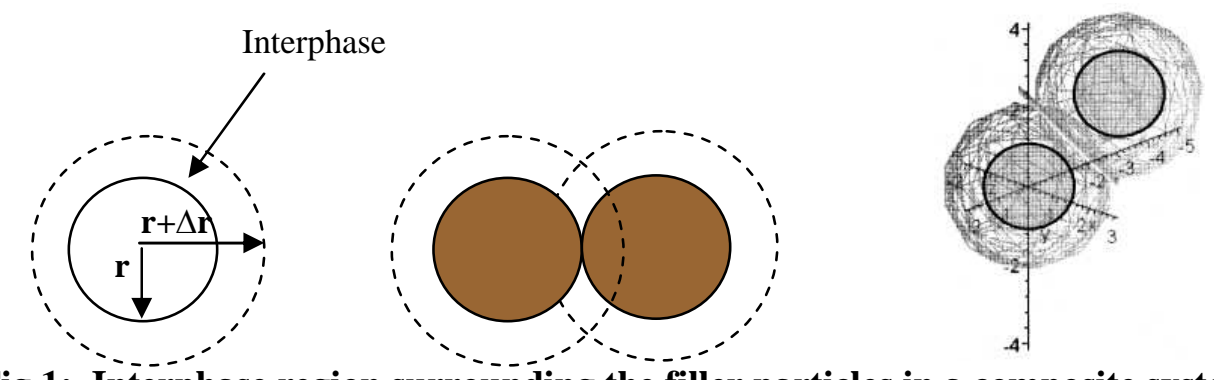

Fig.1: Interphase region surrounding the filler particles in a composite system

\section{INTERPHASE POWER LOW IPL MODEL}

Power law relationships are quite often used in dielectric modeling of composite systems [1]. These relationships model the effective permittivity of two-component systems using the volume fraction of each component according to:

$$
\varepsilon_{c}^{\beta}=\phi_{f} \varepsilon_{f}^{\beta}+\left(1-\phi_{f}\right) \varepsilon_{m}^{\beta}
$$

where $\varepsilon_{\mathrm{c}}, \varepsilon_{\mathrm{f}}$, and $\varepsilon_{\mathrm{m}}$ are the complex dielectric permittivity of the composite system, the filler, and the matrix respectively, $\phi f$ is the volume fraction of filler component of the composite system, and $\beta$ is a dimensionless parameter representing the shape and orientation of the filler particles within the bulk composite [2]. Common application of this model are the linear mixtures model $\beta=1$, the Birchak formula $\beta=0.5$ and the Landau, Lifshitz, Looyenga formula $\beta=0.33$. More generally, for a composite comprised of $n$ number of components, the power law mixtures model may be written as [4]:

$$
\varepsilon_{c}^{\beta}=\sum_{i=1}^{n} \phi_{i} \varepsilon_{i}^{\beta}
$$

where $\varepsilon_{\mathrm{c}}$ and $\varepsilon_{\mathrm{i}}$ are the complex dielectric permittivity of the composite system and any constituent component of the composite respectively, $\phi_{i}$ is the volume fraction of the constituent component. Additional dielectric models for mixtures of composite constituents have been developed, including the Maxwell-Garnett model and the Bruggeman model [10]. Each of these mixture models provides different approaches for predicting the dielectric characteristics of composite systems. These approaches, however, do not provide a comprehensive means to determine both the real and imaginary components of the complex permittivity of composite systems while accounting for interactions between the individual components. The two-component power-law relationship described by equation (1) is easily extended to a three component composite system, as described by:

$$
\varepsilon_{c}^{\beta}=\phi_{f} \varepsilon_{f}^{\beta}+\phi_{i} \varepsilon_{i}^{\beta}+\phi_{m} \varepsilon_{m C}^{\beta}
$$

For a composite model that contains an interphase region, $\phi_{\mathrm{f}}, \phi_{\mathrm{i}}$, and $\phi_{\mathrm{m}}$ represent the volume fraction of the filler component, the interphase region and the matrix component of the composite, respectively, $\varepsilon_{\mathrm{c}}, \varepsilon_{\mathrm{f}}, \varepsilon_{\mathrm{i}}$ and $\varepsilon \mathrm{m}$ are the complex permittivities of the composite, the filler, interphase and matrix regions of the 
composite, respectively. The complex permittivity is given by $\varepsilon_{\mathrm{i}}=\varepsilon_{\mathrm{c}}{ }^{\prime}+\varepsilon_{\mathrm{i}}{ }^{\prime}$, where $\varepsilon_{\mathrm{c}}{ }^{\prime}$ is the dielectric constant and $\varepsilon_{\mathrm{i}}$ " is the dielectric loss. It is important to recognize the distinction between the IPL model and a standard three-component power-law mixture. Therefore, refer to independent composite constituents as (components) and the dependent constituents as (interphase). The distinction between these cases will become more evident with further explanation. The filler volume fraction of equation (3), $\phi_{f}$, is directly measured for a given composite system. The matrix volume fraction is given by $\phi_{\mathrm{m}}=\left(1-\phi_{\mathrm{f}}-\phi_{\mathrm{m}}\right)$. The interphase region volume fraction, $\phi_{\mathrm{i}}$, is dependent upon the filler volume fraction, the filler surface area and the thickness of the interphase region surrounding each filler particle. The interphase volume fraction, $\phi_{i}$, is determined for monodisperse, spherical particles using equation (4) [12] :

$$
\phi_{i}=\frac{4 \pi \phi_{f}}{3} \times \frac{\left((r+\Delta r)^{3}-r^{3}\right)-6 F(3(r+\Delta r)-\Delta r) \Delta r^{2}}{r^{3}}
$$

where $r$ is the radius of the filler particles, $\Delta r$ is the thickness of the interphase region and $\mathrm{F}$ is an overlap probability function. Assuming that, there are no areas of interphase overlap that would reduce the total volume of interphase. Therefore, the interphase volume fraction, ,i, is calculated by:

$$
\phi_{i}=(1-F)\left(S_{f} \Delta r\right) \rho_{f} \phi_{f}
$$

where $S_{\mathrm{f}}$ is the specific surface area of filler (measured in $\mathrm{m} 2 / \mathrm{g}$ ), and $\rho_{\mathrm{f}}$ is the density of filler (measured in $\mathrm{g} / \mathrm{m}^{3}$ ).

The interphase density is assumed to be equal to that of the matrix component since it is comprised of matrix molecules. Typically, the interphase thickness is on the order of one molecular radius of gyration (5 to 20) $\mathrm{nm}$. The determination of the interphase thickness is further described in detail in [11-14]. The interphase overlap probability, $\mathrm{F}$, arises from the proximity of the individual filler particles. As illustrated in Fig. 1, when the filler particles come close together, the interphase regions surrounding each filler particle begin to overlap, thereby reducing the effective interphase volume fraction. The interphase overlap probability is a function of the filler volume fraction, interphase thickness and the shape and size of the filler particles. Approximations have been developed to estimate the overlap of such particles using analytical solutions to percolation models [15-17]. Equations (3) through (5) can be used to complete a generalized, comprehensive model for the prediction of the complex dielectric permittivity of composite systems containing interphase-bonding regions. The bounds, however, are based on a critical assumption that no interaction exists between the components of the composite system, and therefore no interphase region exists.

\section{SELECTED NANO-FILLERS AND POLYMERS FOR INDUSTRIAL MATERIALS}

Nano-fillers such as, Clay mineral used in the polymer industry is kaolinite. Kaolinite is the main constituent of filler clays, significant quantities of other minerals can often be present. The particle shape is the most important characteristic of kaolinite for polymer applications. The platy nature means that clay fillers have a greater effect 
on properties such as viscosity, stiffness and strength, using clay as nano filler gives high levels of flame retardancy to the produced composite of Clay catalyst to be the best filler among nano-fillers industrial materials such as: Fumed Silica is used primarily in silicone rubber and compounds with special polymers or cure systems, and is produced by high temperature gaseous process and is more expensive, and Glass Fibers are among the most versatile industrial materials known today. Also, the most useful feature of Glass Beads is their ability to reduce the density of a product.

Many selected polymers for fabricating industrial materials are used in this paper, such as Acrylonitrile Butadiene-Styrene ABS has been created with rubber particles in order to increase the toughness. ABS has good electrical properties that are fairly constant over a wide range of frequencies. Polyethylene PE applications vary depending upon the grade of resin LDPE, because of its flexibility, is used primarily for prosthetic devices and vacuum formed parts. Polyvinyl Chloride PVC is the most widely used of any of the thermoplasts, it is stronger and more rigid than other general purpose thermoplastic materials. The primary applications for PVC include electrical conduit, and wire insulation. Finally, applications for Epoxy-based materials are extensive and include coatings, adhesives and composite materials such as those using carbon fiber and fiberglass reinforcements. Epoxy resin formulations are important in the electronics industry, and employed excellent electrical insulators and protect electrical components from short circuiting, dust and moisture.

\section{RESULTS AND DISCUSSIONS}

This paper discussed two issues, the first studying effective parameters of PLP model, and the second issue is specifying characteristics of new industrial materials, for the dielectric characteristics of nanocomposite polymeric materials by IPL.

\subsection{Effective Parameters of PLP Model}

Effective parameters of PLP model results investigate the effects of filler permittivity, interphase permittivity, filler surface area or interphase thickness, and filler particle shape.

\subsubsection{Effect of filler permittivity:}

The effective dielectric constant and dielectric losses of the composite system are shown in Fig. 2 with three values of a filler dielectric constant. The effective dielectric constant of the composite increased rapidly with high value of filler dielectric constant, while for a low value of filler dielectric constant, the effective dielectric constant of the composite smoothly decreased with the variation of filler volume fraction from zero to unity as shown in Fig. 2(a). Also, the effective dielectric loss with volume fraction changing from zero to unity, the maximum dielectric loss appears at nearly $20 \%$ filler volume fraction as shown in Fig. 2(b), then smoothly decreased to reach zero at unity volume fraction. For three values of filler complex dielectric permittivity, the effective dielectric loss increased when the filler dielectric permittivity increased. It is cleared that, from these predictions that accounting for the interphase region cause a deviation from linearity of the effective permittivity of the composite system. 


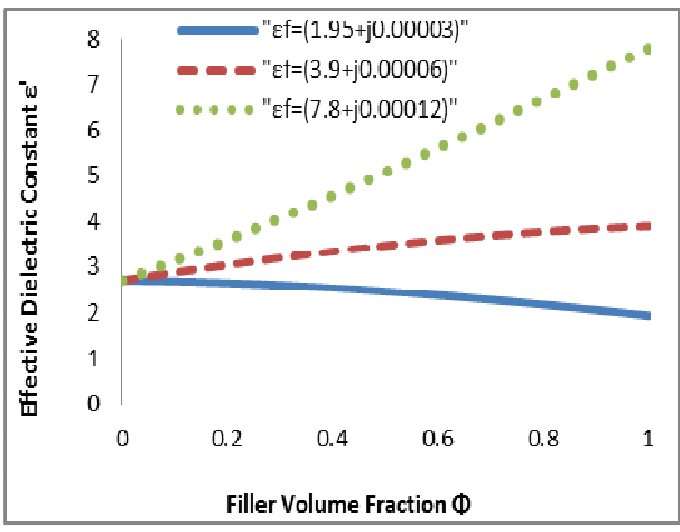

(a) Effective dielectric constant

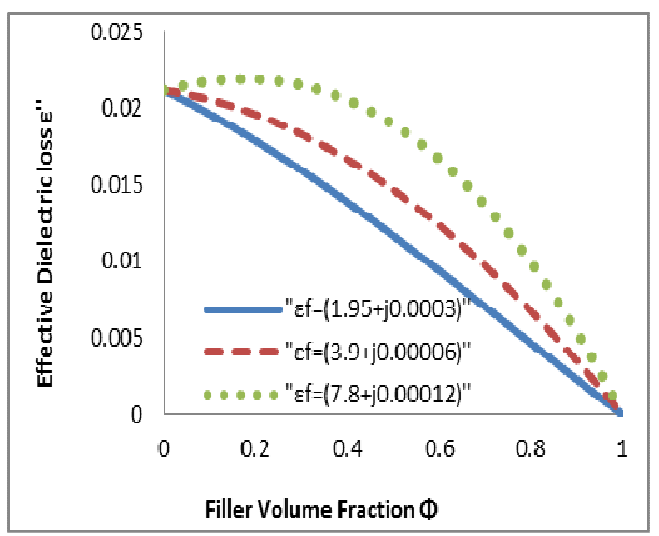

(b) Effective dielectric loss

Fig. 2: Effect of filler permittivity on the effective dielectric constant and effective dielectric loss as a function of filler volume loading

\subsubsection{Effect of interphase permittivity :}

At a critical filler concentration corresponding to the maximum in interphase volume fraction, the interphase permittivity creates a maximum or minimum in the effective permittivity of the composite system as shown in Fig.3. A non-linearity in the effective complex permittivity of the composite system is a function of filler volume fraction. At the filler volume fraction loading from 0.0 to and 1.0, the complex permittivity is equal to that of the polymer component and filler component respectively, but between these limits, the IPL model predicts a complex permittivity of the composite system that is significantly larger than that predicted by conventional mixture models since these models do not account for component interactions of the composite.

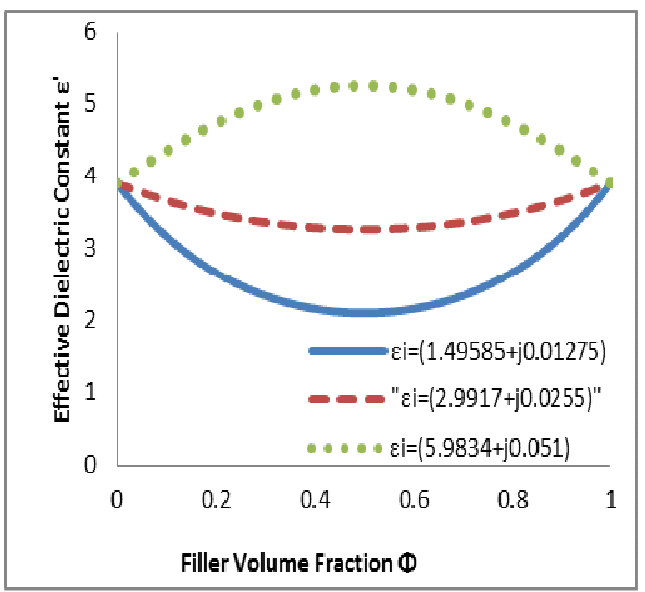

(a) Effective dielectric constant

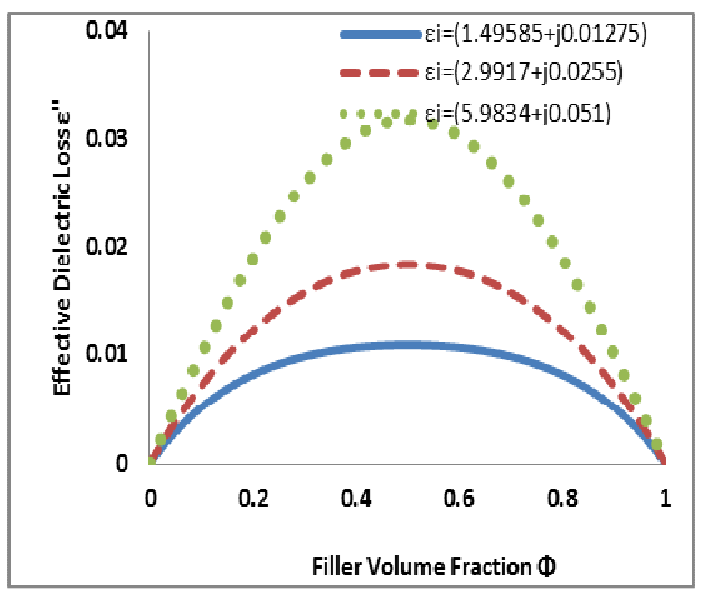

(b) Effective dielectric loss

Fig.3: Effect of interphase permittivity on composite dielectric constant and dielectric losses as a function of filler volume fraction for a composite system 


\subsubsection{Effect of filler surface area :}

A filler diameter is proportional to a squared increase in specific surface area and resultant interphase volume fraction for a spherical particle. For non-spherical particles, the increase in specific surface area and interphase volume fraction is even greater, decreases by increase particle size and shape. A composite system was evaluated using the IPL model, the filler surface area illustrated the results for three values of filler particles surface area $\left(40,64\right.$, and 76) $\mathrm{m}^{2} / \mathrm{g}$, when dielectric polymer and dielectric filler are equally $\left(\varepsilon_{\mathrm{f}}=\varepsilon_{\mathrm{m}}\right)$. For the application as shown in Fig. 4 , by increasing the filler particle surface area a composite system containing an interphase region with a permittivity higher than that of the matrix yields an increase to the effective permittivity. Figure 4(a) shows the effect of filler surface area on composite dielectric constant, and Fig. 4(b) shows the dielectric losses as a function of filler volume fraction for a composite system.

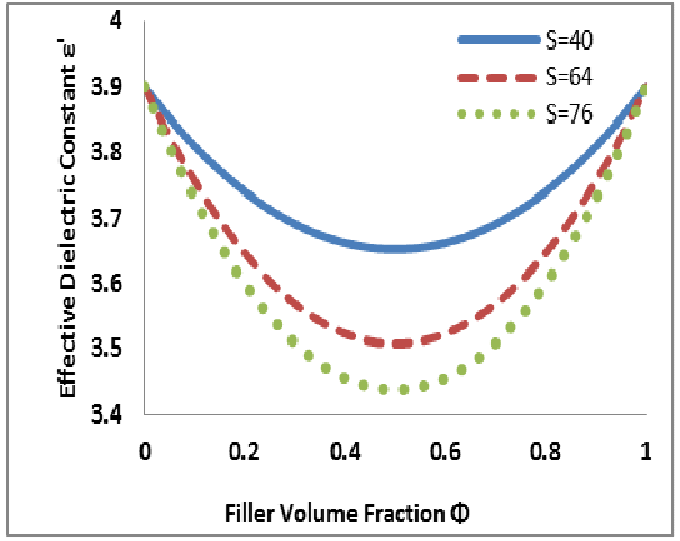

(a) Effective dielectric constant

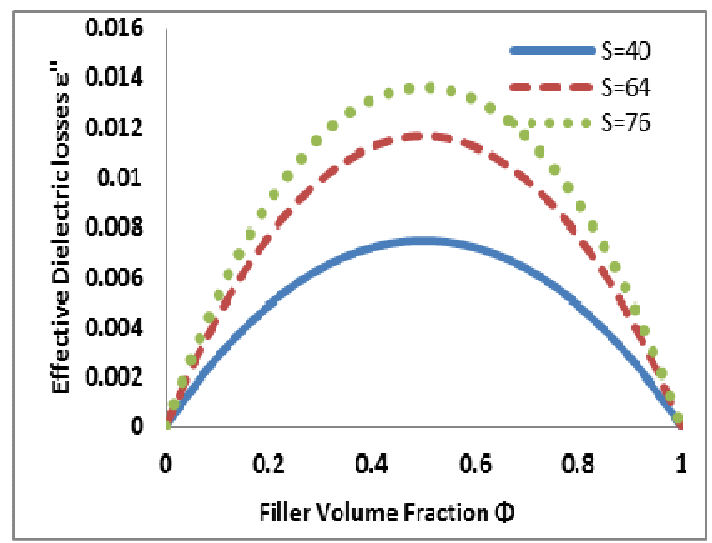

(b) Effective dielectric loss

Fig.4: Effect of filler surface area on composite dielectric constant and dielectric losses as a function of filler volume fraction for a composite system

\subsubsection{Effect of interphase thickness :}

The interphase volume fraction is also dependent upon the thickness of the interphase region, $\Delta \mathrm{r}$. To illustrate this effect, a model composite system has been evaluated using the IPL model. Figure 5 illustrates the effect of increasing the interphase thickness from ( 0.0 to 10$) \mathrm{nm}$ on the composite dielectric constant of this two component system. In real applications, the chemical bonding between the two components of the composite and the chemical structure of the matrix component controls the interphase thickness provided into the chemical structures of interphase regions and their thickness.

\subsubsection{Effect of filler particle shape and orientation:}

For anisotropic composite systems having the dispersed component oriented parallel to the electric field, the value of $\beta$ is greater than 0.3. An application of this type of composite is epitaxial grown composite films. The value of $\beta$ becomes 0.99 . The 
material parameters were utilized in the IPL model to illustrate the effect of the shape parameter, $\beta$ on the effective permittivity of a composite system. The effect of each of these cases $(\beta=-0.97$ and $\beta=0.99)$ is illustrated in Fig.6.

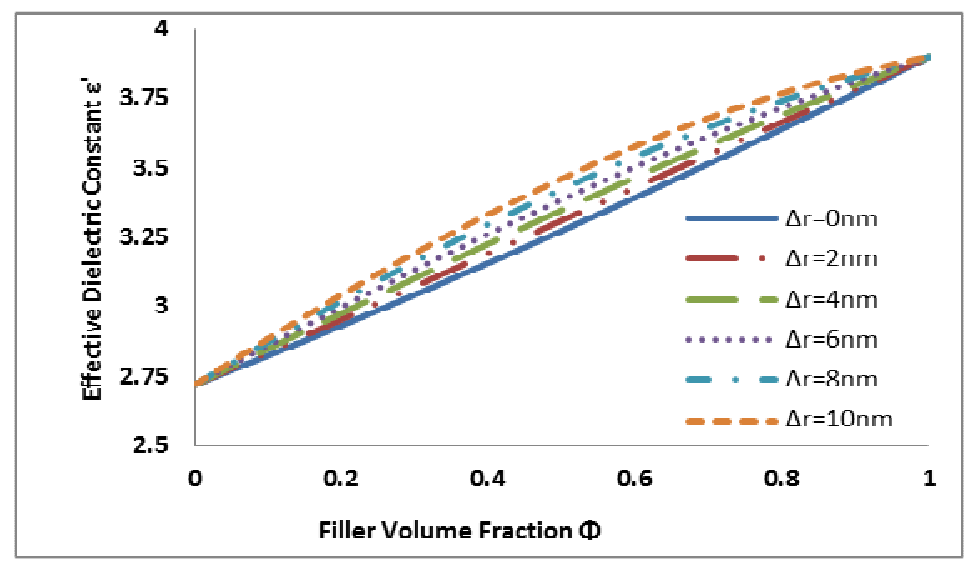

Fig.5: Effect of various interphase thickness on the dielectric constant as a function of filler volume fraction for a composite system

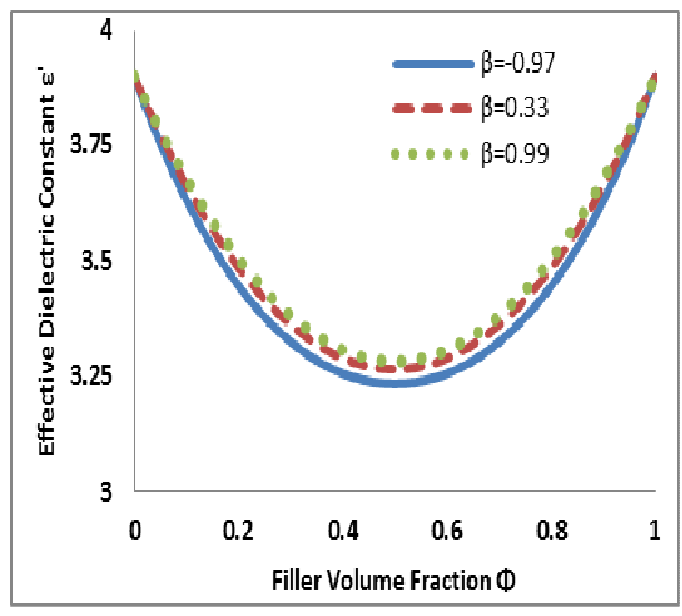

(a) Effective dielectric constant

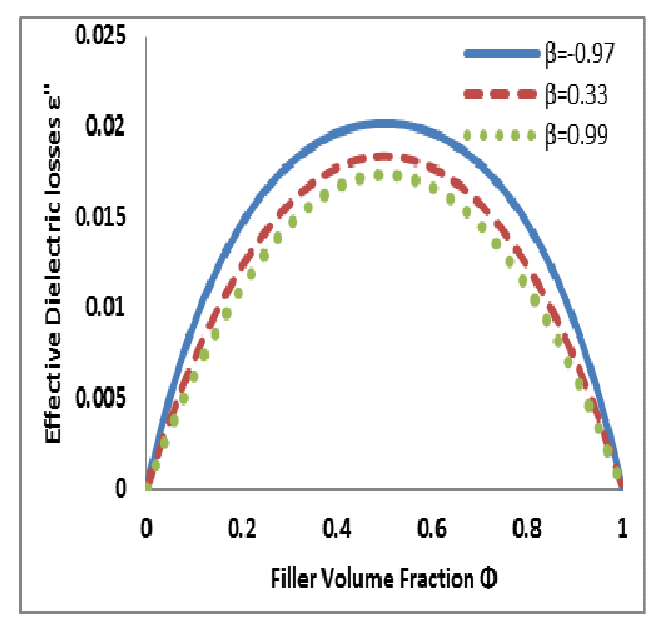

(b) Effective dielectric loss

Fig.6: Effect of particle shape and orientation on composite dielectric constant and dielectric loss as a function of filler volume fraction for a composite system

\subsection{New Industrial Materials}

The IPL model predicts a distinct non-linearity of the effective dielectric constant as a function of filler volume loading. As new industrial insulation materials formed by nano-fillers such as clay, fumed silica, glass fibers, and glass beads is their ability to reduce the cost of a product. Many selected polymers industrial materials are used in this paper, such as ABS, LDPE, and PVC. 


\subsubsection{Effect of nano-fillers on industrial materials:}

Figure 7 shows the effect of each nano-filler industrial materials selected type on the dielectric constant of the composite as the volume fraction of fillers loading. From these simulated results the effective dielectric constant for all polymeric industrial materials deceasing with Clay, and Glass Beads nano-fillers composite, while increasing with Fumed Silica, and Glass Fibers nano-fillers composite. Since Glass Beads and Clay shows the best behavior as nano-filler used for insulation materials, but Glass fibers and Fumed Silica shows the best behavior as nano-filler used for conducting industrial materials.

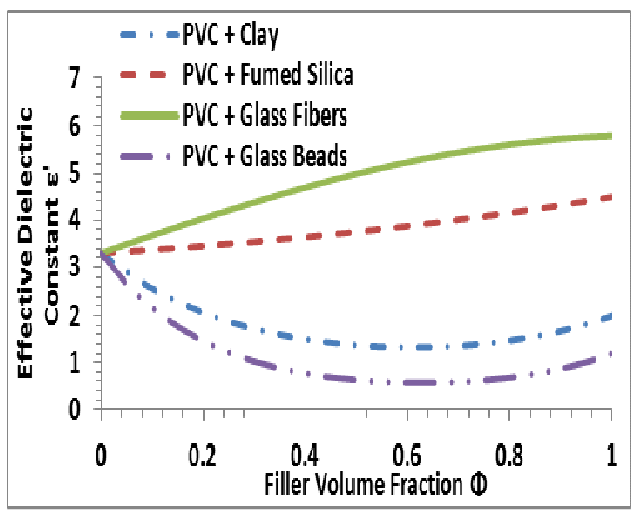

(a) PVC industrial polymer

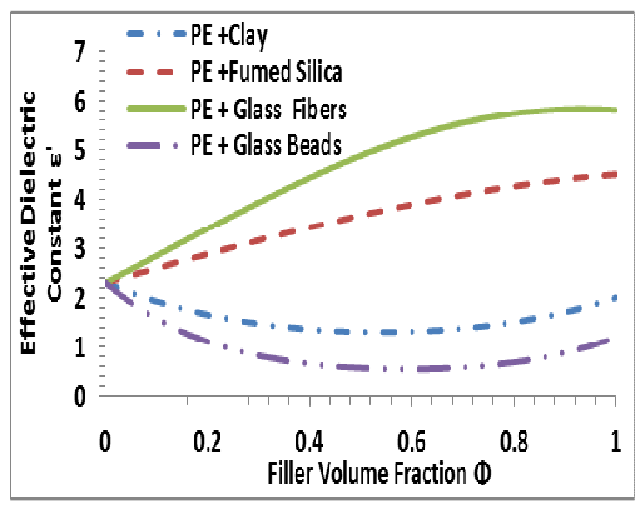

(c) PE industrial polymer

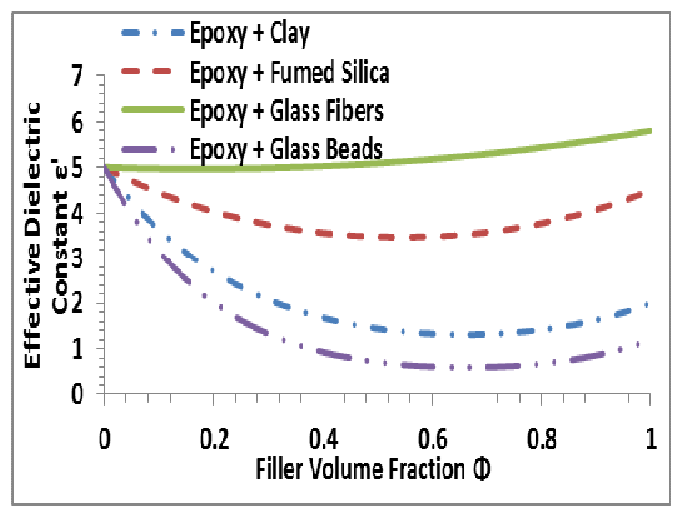

(b) Epoxy industrial polymer

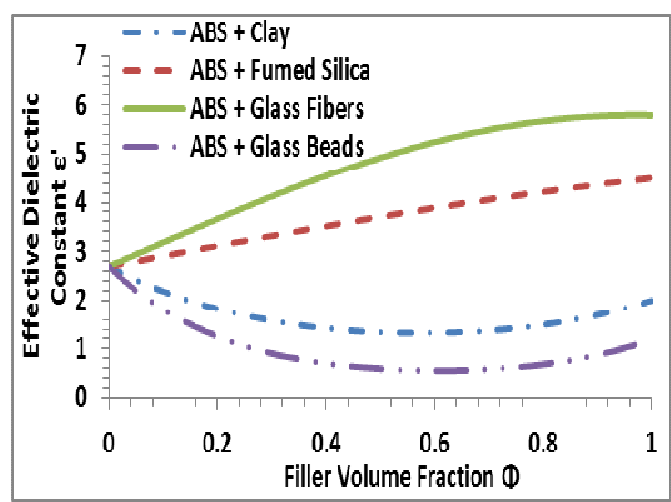

(d) ABS industrial polymer

Fig. 7 Effects of nano-fillers on effective dielectric constant with different industrial polymers

\subsubsection{Effect of filler surface area on industrial materials :}

The magnitude of permittivity deviation from linearity is dependent upon the filler volume fraction, filler surface area, and the interphase permittivity. Figure 8 shows the effect of filler surface area, when it's equal 40 , and $100 \mathrm{~m}^{2} / \mathrm{g}$. By increasing filler volume fraction, the nonlinearity behavior for the dielectric constant for all polymeric 
industrial materials is decreasing up to $55 \%$, after that, the dielectric constant is increasing smoothly, when filler surface area equal to $40 \mathrm{~m}^{2} / \mathrm{g}$ as shown in Fig. 8(a). Figure 8 (b) shows the effective dielectric constant with varying filler volume fraction for all nanocomposite industrial materials whenever filler surface area equal $100 \mathrm{~m}^{2} / \mathrm{g}$.

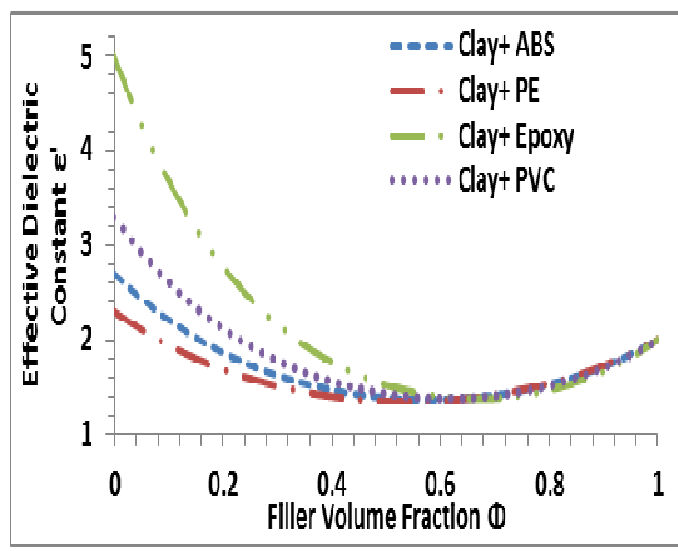

(a) Filler surface area $s=40 \mathrm{~m}^{2} / \mathrm{g}$

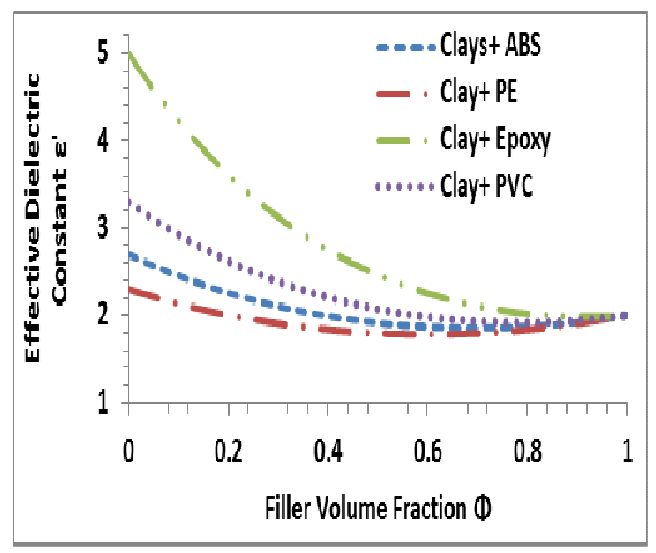

(b) Filler surface area $s=100 \mathrm{~m}^{2} / \mathrm{g}$

Fig. 8: Effect of filler volume fraction on effective dielectric constant for a different nanocomposites industrial materials

\subsubsection{Effect of filler interphase thickness on industrial materials:}

Figure 9 shows that the effective dielectric constant is decreasing for all nanocomposite industrial materials by increasing filler volume fraction at interphase thickness 2, and $10 \mathrm{~nm}$. Figure 9(a) shows Clay with PE nanocomposite has a lowest effective dielectric constant, but Clay with Epoxy nanocomposite has the highest effective dielectric constant up to $35 \%$. Clay with ABS nanocomposite is the highest from $35 \%$ up to $100 \%$ of the filler volume fraction. Figure 9 (b) shows Clay with PE nanocomposite has a lowest effective dielectric constant, while, Clay with Epoxy nanocomposite has that a highest effective dielectric constant from $0 \%$ up to $100 \%$ of the filler volume fraction. Figure 9 shows the effective dielectric constant which decreasing for all nanocomposite industrial materials by increasing filler volume fraction.

\subsubsection{Effect of filler particle shape and orientation on industrial materials}

Filler particle shape has an important effect on the nanocomposite dielectric constant, the value of $\beta$ depending on the orientation of the filler particles in the composite. While increasing the addition of Clay nanoparticles polymers it will decrease the effective dielectric constant of the nanocomposite. Figure 10 shows the different polymer types filled with Clay nanocomposite, the PE gives the lowest dielectric constant between all polymer types, and the Epoxy gives the highest dielectric constant up to $30 \%$ of the filler volume fraction when $\beta=0.33$ as shown in Fig. 10(a). While the ABS up to $25 \%$ of the filler volume fraction when $\beta=-0.97$ as shown in Fig. 10(b). 


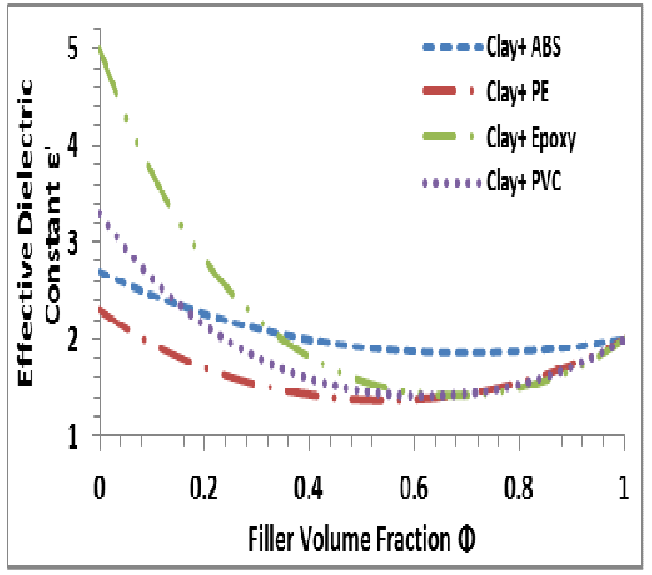

(a) Filler interphase thickness $\Delta \mathbf{r}=\mathbf{2 n m}$

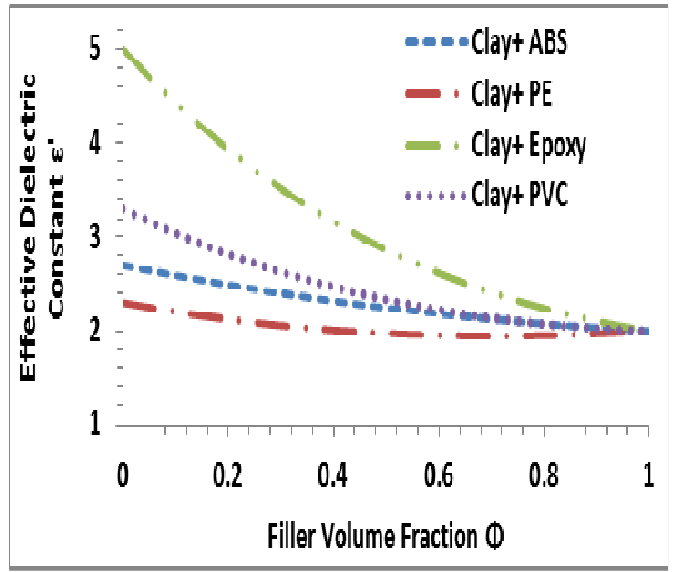

(b) Filler interphase thickness $\Delta \mathrm{r}=10 \mathrm{~nm}$

Fig. 9: Effect of filler volume fraction on effective dielectric constant for different nanocomposites industrial materials

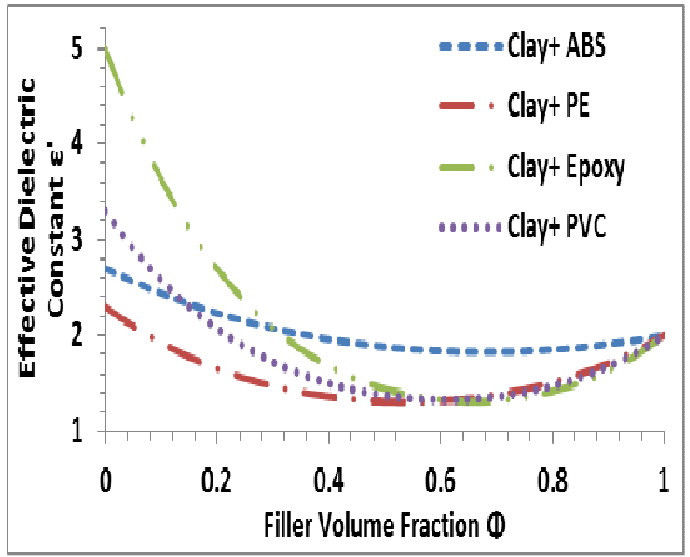

(a) Filler particle shape $\beta=0.33$

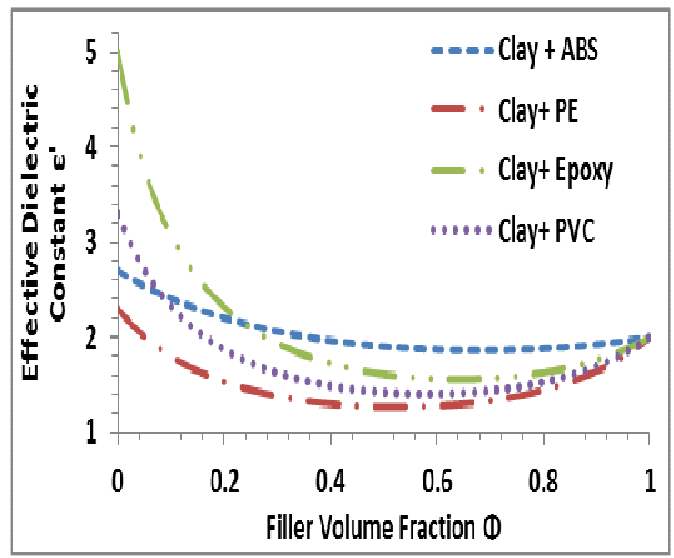

(b) Filler particle shape $\beta=-0.97$

Fig. 10: Effect of filler volume fraction on effective dielectric constant for different nanocomposites industrial materials

\section{CONCLUSION}

IPL model predicts a distinct non-linearity in the effective dielectric constant and dielectric loss as a function of filler volume loading. Since the dielectric characteristics of the interphase region contributes to the overall effective dielectric characteristics of the composite system, and the volume fraction of the interphase region changes nonlinearly with the volume fraction of filler, the permittivity of the composite changes non-linearly as a function of filler loading. The effect of increasing the interphase thickness in a composite system tends to an increase for the effective permittivity, 
while, the effect of the shape parameters on the effective permittivity of a composite system. The interphase permittivity is generally within approximately $10 \%$ of the matrix phase. Clay has a good behavior as a nano-filler used for insulation materials and has an effective dielectric characteristic for different polymer industrial materials of nanocomposite insulation materials by IPL. Clay nano-filler can create novel costless insulation industrial materials for getting smoothly decreased effective dielectric constant with the variation of filler volume fraction of the nanocomposite material. Increasing Clay filler surface area and its interphase thickness more smoothly decreased the effective dielectric constant of the nano-composite, and the lowest effect at $55 \%$. Clay with Epoxy nanocomposites is the highest reduction in effective dielectric constant, but Clay with PE nanocomposites has the lowest effect by increasing filler volume fraction.

\section{ACKNOWLEDGMENT}

The present work was supported by the Science and Technology Development Fund (STDF), Egypt, Grant No: Project ID 505.

\section{REFERENCES}

[1] S. O. Nelson, "Measurement and Calculation of Powdered Mixture Permittivities', IEEE Trans. Inst. Meas., Vol. 50, pp. 1066-1070, 2001.

[2] D. Gershon, J. P. Calame, and A. Birnboim, "Complex Permittivity Measurements and Mixing Laws of Alumina Composites', J. Appl. Phys., Vol. 89, pp. 8110-8116, 2001.

[3] M. S. Ozmusul, and R. C. Picu, "Elastic Moduli of Particulate Composites with Graded Filler-Matrix Interfaces', Polymer Composites, Vol. 23, No. 1, pp. 110119, 2002.

[4] J. Qu, and C. P. Wong, "Effective Elastic Modulus of Under fill Material for Flip-Chip Applications', IEEE Trans. Components and Packaging Techn., Vol. 25, pp. 53-55, 2002.

[5] H. Vo, and F. G. Shi, “Towards Model-Based Engineering of Optoelectronic Packaging Materials: Dielectric Constant Modeling', Microelectronics J., Vol. 33, pp. 409- 415, 2002.

[6] H. Vo, M. Todd, F. Shi, A. Shapiro, and M. Edwards, "Towards Model-Based Engineering of Under fill Materials: CTE Modeling', Microelectronics J., Vol. 32, pp. 331-338, 2001.

[7] M. Todd, and F. Shi, "Molecular Basis of the Interphase Dielectric Properties of Microelectronic and Optoelectronic Packaging Materials', IEEE Trans. Components Packaging Techn., Vol. 26, No. 3, pp. 667-672, 2003.

[8] M. Todd, and F. Shi, "Characterizing the Interphase Dielectric Constant of Polymer Composite Materials: Effect of Chemical Coupling Agents', J. Appl. Phys., Vol. 94, pp. 4551-4557, 2003.

[9] T. Tanaka, G. C. Montanari, and R. Mulhaupt, "Polymer Nanocomposites as Dielectrics and Electrical Insulation - Perspectives for Processing Technologies, Material Characterization and Future Applications", IEEE Trans. Dielectr. Electr. Insul., Vol. 11, pp. 763-784, 2004. 
[10] Y. Cao, P. C. Irwin, and K. Younsi, "The Future of Nano-dielectrics in the Electrical Power Industry”, IEEE Trans. Dielectr. Electr. Insul., Vol. 11, pp. 797807, 2004.

[11] J. K. Nelson, and Y. Hu, "Nanocomposite Dielectrics - Properties and Implications", J. Phys. D: Appl. Phys., Vol. 12, pp. 914-928, 2005.

[12] J. C. Fothergill, J. K. Nelson, and M. Fu, "Dielectric Properties of Epoxy Nanocomposites Containing $\mathrm{TiO}_{2}, \mathrm{Al}_{2} \mathrm{O}_{3}$ and $\mathrm{ZnO}$ Fillers", IEEE Conf. Electr. Insul. Dielectr. Phenomena (CEIDP), pp. 406-409, 2004.

[13] E. Tuncer, I. Sauers, D. R. James, A. R. Ellis, M. P. Paranthaman, T. Aytug, S. Sathyamurthy, K. L. More, J. Li, and A. Goyal, "Electrical Properties of Epoxy Resin based Nano-Composites", Nanotechnology, Vol. 18, pp. 1-6, 2007.

[14] S. L. Gao, and E. Mader, "Characterization of Interphase Nanoscale Property Variations in Glass Fiber Reinforced Polypropylene and Epoxy Composites", Composites Part A, Vol. 33, pp. 559-576, 2002.

[15] S. C. George, and S. Thomas, "Transport Phenomena Through Polymeric Systems", Progress in Polymer Science, Vol.26, No. 6, pp. 985-1017, 2001.

[16] T. Seelig, and E. Van Der Giessen, "Localized Plastic Deformation in Ternypolymer blends", Int J Solids Struct, Vol.39, pp.3505-3522, 2002.

[17] S. F. Wang, Y. Hu, R.W. Zong, Y. Tang, Z. Y. Chen, and W. C. Fan, "Preparation and Characterization of Flame Retardant ABS/Montmorillonite Nanocomposites", Appl. Sci, Vol.25. No. 1, pp.49-55, 2004.

[18] T. J. Lewis, "Interfaces: Nanometric Dielectrics", Journal of Physics D Applied Physics, Vol.38, pp.202-212, 2005.

[19] S. Singha, and M. J. Thomas, "Dielectric Properties of Epoxy Nanocomposites", IEEE Trans. Dielectr. Electr. Insul., Vol. 15, pp. 12- 23, 2008.

[20] N. Lombardo, "A Two-Way Particle Mapping for Calculation of the Effective Dielectric Response of Graded Spherical Composites", Composites Science and Technology, Vol.67, pp.728-736, 2007.

[21] K.W. Yu, G.Q. Gu, and J. P. Huang, "Dielectric Response of Spherical Particles of Graded Materials", Conductung-Materials, 2002.

\section{من بوليمرات المواد الصناعية نموذج لمحاكاة سلوك العازلات لمركبات النانو}

$$
\begin{aligned}
& \text { ان المستوي الهيكلي الكمبائسي للبوليبرات المركبة والتتي تشدل منطقة التداخل تحتوي علي جزيئات من مصفوفة } \\
& \text { البوليبر والتي إزتبطت بسطح حبييات النانو المضافة للمركب تحت مسدي "حبز التداخل" والتي تحدث نتيجة }
\end{aligned}
$$

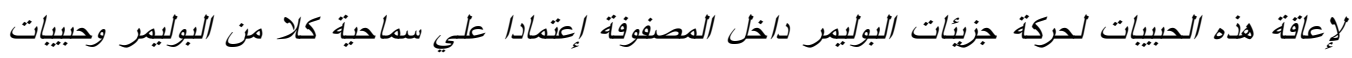

$$
\begin{aligned}
& \text { النانو ومجال التداخل ونسب كلا هنهم داخل المركب. ومن خال هذا البحث تم دراسة تأثير حيز التداخل علي } \\
& \text { عدد من المواد المركبة الصناعية مع تغبير نوع الحبييات داخل المركب، كما تم دراسة تأثبر تغبيير مساحة سطح } \\
& \text { الحبييات علي المركب ودراسة خصائص العزل والتوصبل نتيجة لوجود هذه الحبييات مختلطة هع جزيئات } \\
& \text { الدصفوفة في حيز التداخل للمركب. كما بخلص هذا البحث الي كبفية ابتكار مواد عازلة صناعية جبيدة رخيصة } \\
& \text { التكلفة باستخد/م /حدث تقنيات النانوتكنولوجي. }
\end{aligned}
$$




\section{AUTHORS' INFORMATION}

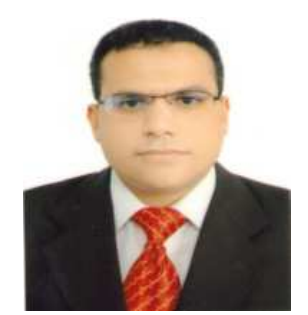

Ahmed Thabet was born in Aswan, Egypt in 1974. He received the BSc (HIE) Electrical Engineering degree in 1997, and MSc (HIE) Electrical Engineering degree in 2002 both from High Institute of Energy, Aswan, Egypt. PhD degree had been received in Electrical Engineering in 2006 from El-Minia University, Minia, Egypt. He joined with Electrical Power Engineering Group of Faculty of Energy Engineering in South Valley University as a Demonstrator at July 1999, until; he held Associate Professor position at October 2011 up to date. His research interests lie in the areas of analysis and developing electrical engineering models and applications, investigating novel nano-technology materials via addition nano-scale particles and additives for usage in industrial branch, electromagnetic materials, electroluminescence and the relationship with electrical and thermal ageing of industrial polymers. A lot of mobility's has investigated for supporting his research experience in UK, Finland, Italy, and USA ...etc. On 2009, he had been a Principle Investigator of a funded project from Science and Technology development Fund "STDF" for developing industrial materials of ac and dc applications by nano-technology techniques. He has been established first NanoTechnology Research Centre in the Upper Egypt :

(http://www.aswan.svu.edu.eg/nano/index.htm). He has more than 55 publications which have been published and under published in IEEE journals and conferences and held in Nano-Technology Research Centre website:

(http://www.ghson.net/FOLDERS_INDEX/nano/dr_athabet.htm).

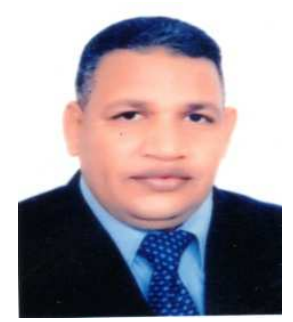

Y. A. Mobarak was born in Egypt. He received his B.Sc. and M.Sc. degrees in electrical engineering from South Valley University, Aswan, Egypt, in 1997 and 2001 respectively and Ph.D. from Cairo University, Egypt, in 2005. He joined Electrical Engineering Department, High Institute of Energy, South Valley University as a Demonstrator, as an Assistant Lecturer, and as an Assistant Professor during the periods of 1998-2001, 2001-2005, and 2005-present respectively. He joined Artificial Complex Systems, Hiroshima University, Japan as a Researcher 2007-2008. Also, he joined King Abdul-Aziz University, faculty of Engineering at Rabigh from 2010 to present. His research interests are power system planning, operation, and optimization techniques applied to power systems. Also, his research interests are Nanotechnology materials via addition nano-scale particles and additives for usage in industrial field. (E-Mail: y.a.mobarak@gmail.com) 